interference on computed tomography and MRI when used during follow-up, and it is easy to perform. Combined with a mesh or muscular flap, it provides both airtight and watertight closure of the chest wall.

\section{References \\ 1. Mansour KA, Thourani VH, Losken A, Reeves JG, Miller JI Jr, Carlson GW, et al. Chest wall resections and reconstruction: a 25-year experience. Ann Thorac Surg. 2002;73:1720-5; discussion 1725-6.}

2. Khalil el-SA, El-Zohairy MA, Bukhari M. Reconstruction of large full thickness chest wall defects following resection of malignant tumors. J Egypt Natl Canc Inst. 2010;22:19-27.

3. Lardinois D, Müller M, Furrer M, Banic A, Gugger M, Krueger T, et al. Functional assessment of chest wall integrity after methylmethacrylate reconstruction. Ann Thorac Surg. 2000;69:919-23.

4. Bottlang M, Helzel I, Long WB, Madey S. Anatomically Contoured Plates for Fixation of Rib Fractures. J Trauma. 2010;68:611-5.

5. Coonar AS, Qureshi N, Smith I, Wells FC, Reisberg E, Wihlm JM. A novel titanium rib bridge system for chest wall reconstruction. Ann Thorac Surg. 2009;87:e46-8.

\title{
Transapical aortic valve (JenaValve) implantation for severe aortic insufficiency and aortic aneurysm
}

\author{
Friederike Schlingloff, MD, Christian Frerker, MD, Ulrich Schäfer, MD, and Ralf Bader, MD, Hamburg, \\ Germany
}

Transapical transcatheter aortic valve implantation has become a valid treatment option for severe aortic stenosis in patients who are at high risk or are not operative candidates. ${ }^{1}$ Various self-expanding (CoreValve; Medtronic Inc, Minneapolis, Minn) or balloon-inflatable (Sapien XT; Edwards Inc, Irvine, California) valves are currently widely used. Recently, transcatheter aortic valve implantation has also been used to treat pure aortic regurgitation. ${ }^{2}$ Several cases in which the CoreValve has successfully been used have been reported. ${ }^{3,4}$ Because conventional transcatheter aortic valve implantation prostheses usually need calcification of the native valve for anchoring, however, their use is limited and not free of device embolization. The JenaValve (JenaValve Technology GmbH, Munich, Germany) is a self-expandable valve with 3 metal feelers that allows anatomically correct positioning within the native valve and can be used in a transapical approach. The probe elements are placed into the native cusps, and the valve is then clipped onto the leaflets with a "paper clip" mechanism and released from the catheter. No rapid-pacing is needed, because the valve is instantly fully functional. The JenaValve does not need calcification of the native valve for anchoring of the prosthesis and thus seems well suited for the use in pure aortic regurgitation.

From the Asklepios Klinik St Georg, Hamburg, Germany.

Disclosures: Authors have nothing to disclose with regard to commercial support. JenaValve is a trademark of JenaValve Technology GmbH, Munich, Germany.

Received for publication April 11, 2013; revisions received May 14, 2013; accepted for publication May 23, 2013; available ahead of print July 15, 2013.

Address for reprints: Friederike Schlingloff, MD, Department of Cardiac Surgery, Asklepios Klinik St Georg, Lohmühlenstrasse 5, 20099 Hamburg, Germany (E-mail: f.schlingloff@asklepios.com).

J Thorac Cardiovasc Surg 2013;146:e40-1

$0022-5223 / \$ 36.00$

Copyright (c) 2013 by The American Association for Thoracic Surgery

http://dx.doi.org/10.1016/j.jtcvs.2013.05.029
Its value in treating aortic stenosis has been shown in recent publications. ${ }^{5}$ Treatment of aortic regurgitation in combination with aortic aneurysm usually warrants aortic root replacement, however, with aortic valve replacement as a conventional open procedure. We report a case of the successful use of the transapical JenaValve as an off-label approach in a patient with pure aortic insufficiency and aortic aneurysm.

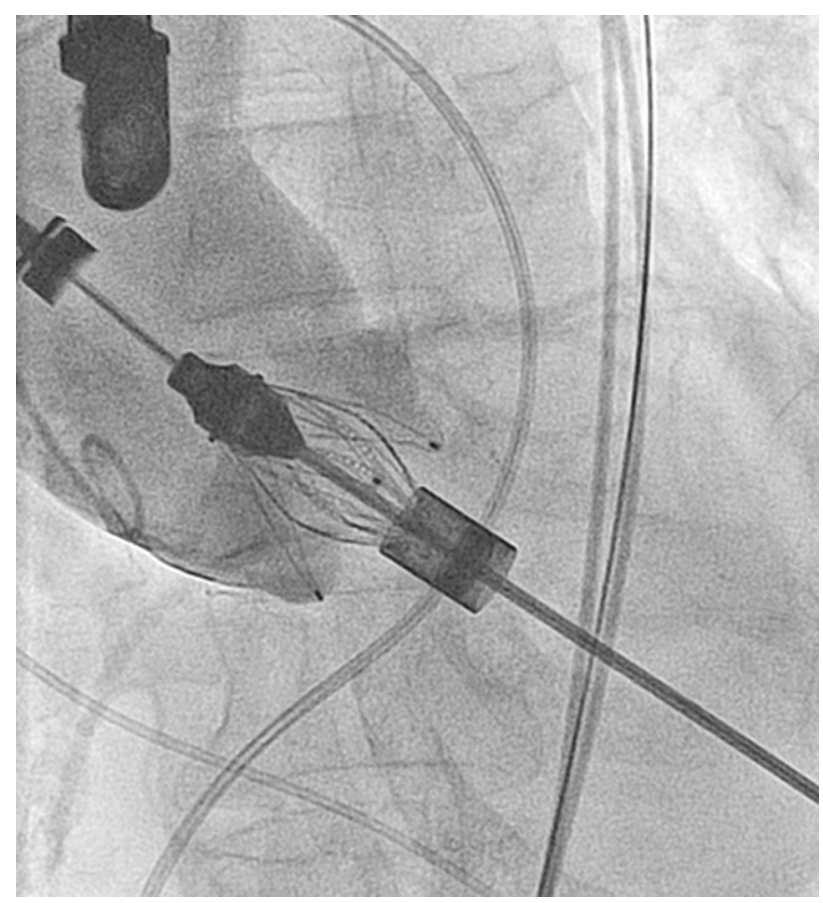

FIGURE 1. After the valve was directly inserted into the annulus, the feelers were exposed and positioned at the base of the aortic cusps with fluoroscopic confirmation. 


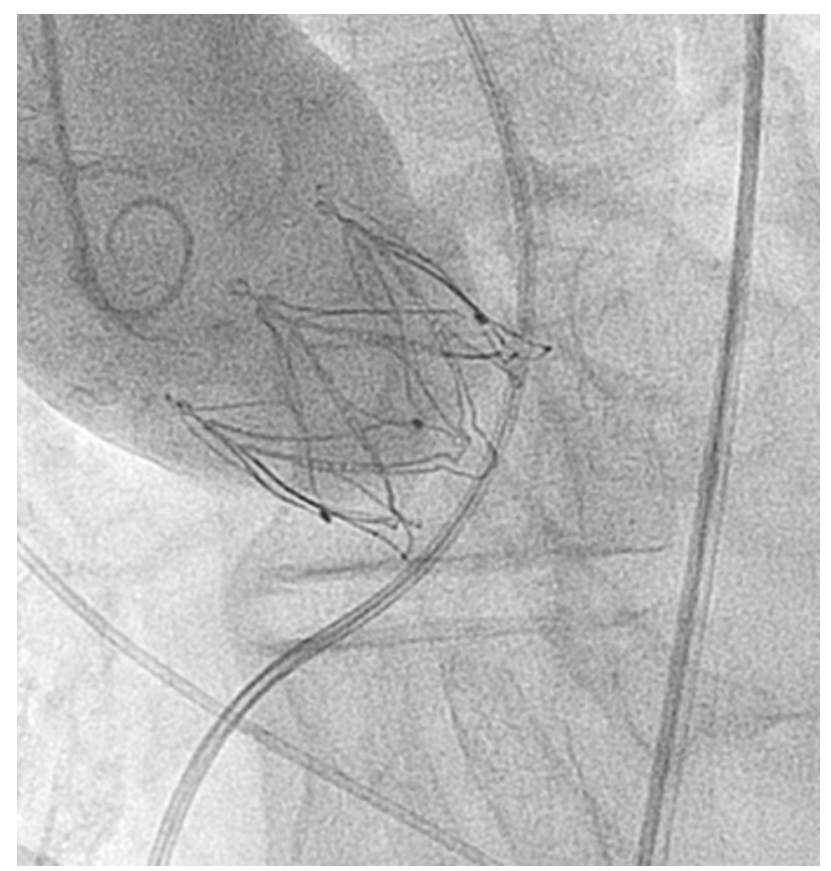

FIGURE 2. On deployment, the nitinol stent expanded and was safely anchored in the native valve annulus.

\section{CLINICAL SUMMARY}

A 70-year-old woman presented at our institution with acute cardiac failure from severe aortic regurgitation. A multislice spiral computed tomographic scan revealed an aneurysm of the ascending aorta as large as $56 \mathrm{~mm}$ in diameter. There was no coronary artery disease visible on angiography. With a euroSCORE II of $5.5 \%$ and a Society of Thoracic Surgeons score of $13 \%$, the patient clearly had no indication for a transcatheter procedure. During discussions, however, the patient persistently refused cardiac surgery, even when confronted with the risk of progress and possible rupture of the aneurysm. It became clear that the patient had been admitted to another department of cardiac surgery before, where surgery had been discussed and she had also refused it. The patient had left that hospital against medical advice. After further discussion with cardiac surgeons and cardiologists of the heart team, the patient would only agree to a transcatheter approach. A transapical valve implantation was planned to reduce "contact" with the ascending aorta to a minimum.

The procedure was performed in the hybrid operating room with a team consisting of cardiologists and cardiothoracic surgeons. The transapical access was prepared in the typical way. The apex was punctured in the middle of the purse-string sutures, and a regular J-wire was introduced with successive insertion of a $6 \mathrm{~F}$ sheath. Because of the complex anatomy, 2 pigtail catheters were introduced for better visualization. Valvuloplasty was omitted, and the valve was directly inserted into the annulus. Subsequently, the feelers were exposed and placed at the base of the aortic cusps. Correct positioning was confirmed on fluoroscopy (Figure 1). In a second step, the prosthesis was deployed during accelerated pacing ( 120 beats $/ \mathrm{min}$ ). The nitinol stent expanded and was safely anchored in the native valve annulus (Figure 2). No paravalvular leak was found on immediate echocardiographic and angiographic control. The chest wall and incision were closed in routine fashion.

The patient was in hemodynamically stable condition immediately after the procedure and was brought to the intensive care unit. Discharge from the hospital was possible on the 9th postoperative day without any complications. Repeated echocardiographic controls demonstrated a persistent excellent result with no leak.

\section{DISCUSSION}

In this case, there was no indication for a transcatheter procedure other than the patient's definite refusal of an open procedure. Progression of the aneurysm is likely, although there could be a stabilizing effect through a diminished pressure amplitude after valve implantation. We still believe that the transcatheter approach should be restricted to the original group of patients who are not operative candidates or who face a high risk during conventional open surgery. With second-generation valves such as the JenaValve, there could be an expanding landscape of indications in the future. The special clip mechanism of the JenaValve is an appealing concept for patients without calcification of the aortic cusps. Implantation of the JenaValve, as shown in this case, seems uncomplicated, because the feelers enable exact and anatomically correct positioning. Nevertheless, long-term data on the performance of these valves in these particular patients is needed for the future.

\section{References}

1. Walther T, Thielmann M, Kempfert J, Schroefel H, Wimmer-Greinecker G, Treede H, et al. One-year multicentre outcomes of transapical aortic valve implantation using the Sapien XT valve: the PREVAIL transapical study. Eur J Cardiothorac Surg. 2012;43:986-92.

2. Bleiziffer S, Mazzitelli D, Nöbauer C, Ried T, Lange R. Successful treatment of pure aortic insufficiency with transapical implantation of the JenaValve. Thorac Crdiovasc Surg. January 23, 2013 [Epub ahead of print].

3. Sarkar K, Sardella G, Romeo F, De Benedictis M, Tarsia G, Iadanza A, et al. Transcatheter aortic valve implantation for severe regurgitation in native and degenerated bioprosthetic aortic valves. Catheter Cardiovasc Interv. 2013;81:864-70.

4. Hildebrandt H, Erbel R, Kahlert P. Compassionate use of the self-expandable Medtronic CoreValve prosthesis fort he treatment of pure aortic regurgitation in a patient at prohibitive risk for surgical valve replacement. Catheter Cardiovasc Interv. November 29, 2012 [Epub ahead of print].

5. Treede H, Mohr F, Baldus S, Rastan A, Ensminger S, Arnold M, et al. Transapical transcatheter aortic valve implantation using the JenaValve ${ }^{\mathrm{TM}}$ system: acute and 30-day results of the multicentre CE-mark study. Eur J Cardiothorac Surg. 2012;41:e131-8. 